ELORE (ISSN 1456-3010), vol. 20 - 1/2013.

Julkaisija: Suomen Kansantietouden Tutkijain Seura ry.

[http://www.elore.fi/arkisto/1_13/petitt.pdf]

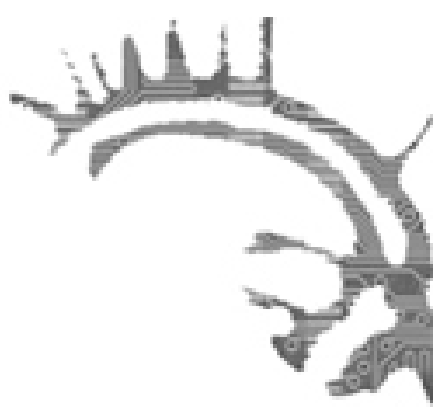

\title{
Article \\ COWBOY MASCULINITIES IN HUMAN-ANIMAL RELATIONS ON A CATTLE RANCH
}

$\underline{\text { Andrea Petitt }}$

\section{INTRODUCTION}

The cowboy, as well as the society surrounding him, has often been seen as holding ultimate masculine qualities. It is common that the image of a cowboy is used to describe these characteristics, even far away from the country setting. The descendant of this image, the contemporary cowboy and his lifestyle, is still often perceived from afar as the archetype of macho culture. The epithet "cowboy" is often used to describe a rough, careless, daring and macho person, not the least in the treatment of animals. From Malamud $(2007,231)$ we learn that what is named "television's cowboy naturalists" includes "inappropriately intrusive" ways of physically grappling with the animals. Birke $(2007,327)$ discusses, referring to Arluke's (1992) research on primate labs, the difference between the "ethical culture" of what he calls "cowboys" and "animal people", in which the cowboys are macho, uncaring and dominate the animals they have contact with, whereas the animal people are compassionate and caring. This description of the cowboy implies traits of a traditional, heterosexual, macho masculinity, and is characteristic for literature and in daily talk. However, the cowboys on the ranch where I conducted fieldwork repeatedly expressed their admiration for skills such as communicating with a horse with a light hand or quietly moving a large number of cows without aggression or turmoil. Inspired 
by this empirical contemplation, the aim of this paper is thus to problematise the display of masculinities in cowboy-cow/horse interaction. After short background information and introduction to the methods used, this article engages with literature on representation and embodied identity, then goes on to focus on the heteronormative, macho and traditionally masculine cowboy, and finally explores alternative cowboy masculinities, before offering some concluding remarks.

\section{BACKGROUND AND METHODS}

In his paper on human-animal relations in cattle ranching, Colter Ellis (2007) underlines the idea that rural masculinities have been crucial in forming the American cultural understanding of what a "real man" should be, which in turn is strongly influenced by the mystique of the cowboy, but that there is no previous research on masculinities within cattle production. Whereas Ellis concentrates on the ranchers' emotional attachment to and detachment from their animals, this paper explores how animals are crucial in the construction of multiple masculinities. Jo Little and Michael Leyshon (2003) argue in their article on embodied rural geographies for a nuanced exploration of embodiment in a rural context that goes beyond the demonstration of a stereotypical representation of masculinity. Thompson (2010) uses a post-binary approach to show the complexity of human-animal relations in Spanish mounted bullfighting, and to argue that the line between human and animal is blurred. A non-binary take on cowboy-animal relations is useful in the sense that all animals are not treated as simply "animals", but specifically as horses or cattle. Further, the cowboy-horse or cowboy-cow relations are themselves complex and not the least so in how they are used to display an array of masculinities.

When asked what skills are important in order to be a good cowboy, the manager of the ranch, with some 40 years of "cowboying" experience, explained that a cowboy needs to be a good horseman, a good stockman and a good roper. In other words, he needs to know how to handle a horse, how to "read" cows and how to throw a rope from horseback to catch a calf on the ground, expressing how central the human-animal relation is for the concept of the contemporary working cowboy. This paper problematises human-animal relations between cowboys, horses and cows that meet on a daily basis on a working cattle ranch. The focus is on how masculinities play a part in the interaction between cowboy and horse/cow in everyday life on the ranch and how animals are used to construct or display different masculinities. Without denying the importance of the traditional associations with cowboy behaviour, this paper explores a more nuanced picture of the embodied human-animal interactions on the ranch in relation to cowboy masculinities. In addition to the traditional macho, heteronormative masculinity, the importance of responsibility, calmness, technical finesse, and sensitivity in the creation and display of the cowboy masculinity is discussed.

The study draws on recent literature from the fields of cultural anthropology, cultural geography, gender studies and anthrozoology. Furthermore, data is used in this study that was collected with the help of semi-structured interviews and participant observation on 
a working cattle ranch in British Colombia, Canada. In order to get an understanding of the everyday life on the ranch, I made arrangements to work full time on a cowboy crew for six weeks, in exchange for food and board at the homestead, while being open and upfront with the academic purpose of my stay. In the evenings, and sometimes from horseback during the day, I conducted interviews with the manager and all the eight cowboys on the crew, as well as the five women on the ranch, holding various jobs such as cooks, a yard worker, and a former cowgirl staying home with children. All names have been changed for anonymity. This data was originally gathered for a master's thesis in anthropology at the University of Montreal, published in 2010, and is used in this paper while drawing on a different theoretical framework. A thematic analysis was conducted with material from both interviews and participant observation, in which the data was codified into categories containing information about the respective themes identified (Malterud 1998).

Ranching in Canada is commonly associated with the middle and western provinces of the country, where the open ranges allow for larger-scale meat production. However, many people in the eastern part of the country are not aware that there are still cowboys on these ranches. In the west of Canada, some cattle ranches still function in many ways as they always have, with a cowboy crew living at the homestead, following the cattle up into the mountains, setting up camps throughout the summer and fall, and with the cowboys working on horseback. It was on such a ranch that I joined the cowboy crew during the calving season in the spring of 2009. The operation, located to the west of the Rocky Mountains and a two-hour drive from the nearest town, was then made up of a cowboy crew of eight, a farming crew of three, two cooks, an administrator, a manager and a seasonal irrigation crew ranging from two to ten people. The ranch is close to a million acres, with approximately 5000 head of cattle depending on the season, and something around forty horses. The cattle are divided up into different fenced areas and moved according to certain grazing and breeding patterns. The horses run free in the mountains and are taken in a few at a time to be ridden for a few months and then let back out again.

\section{REPRESENTATION AND EMBODIED IDENTITY}

That animals represent certain things in the eyes and minds of specific humans is clear. In some groups where the human-animal relation is at the centre front of everyday life, the animal is understood as representing an aspect of the human. In Evan, Kalich and Forsyth's (2007 [1998]) account on dogfights and dog owners, the dog is perceived as representing the masculinity of the owner, a masculinity that they classify as belonging to a white working class of the southern United States. If the dog does not perform well - fight bravely until death or victory, that is - it is killed by its owner in order to restore his masculinity. The traits of the dog are thus transmitted to the owner and its failure to produce the desired qualities requires the ultimate and violent disassociation of the owner from the dog. 
Comparing this with cowboy-animal relations, the horse constitutes a good example. For most of the cowboys on the crew, there was a nostalgic notion that work on horseback represented "the old times" in positive terms. Here, the cowboy rides the horse in his work every day, and it is the way in which the horse and the rider interact that is the important aspect of the experience, rather than the horse itself. This nostalgia for the countryside way of life from the past is often referred to in the literature on rural masculinities as a longing for an identity close to nature, where the traditional elements of heteromasculinity, such as physical fitness, endurance, determination and control of the environment, are central (Little 2007; Little \& Panelli 2003). For the cowboys, to experience nature from the back of a horse is a crucial aspect of this nostalgia. This was evident from their comments on the traditional way of working employed on this particular ranch where they spend every day on a horse, which was the reason why several of them had chosen to work there. This longing for the physical traits and conditions of traditional masculinity thus draws on the horse for representation.

The cowboy on the ranch, as opposed to the dog owner, did not select the horse he rode, and the wild or calm temperament of the horse did not seem to rub off on the perception of the rider. However, the way in which the latter responded to the horse's actions was observed, commented on and judged by the colleagues and the rider himself. The concept of the horse carries an undeniable symbolism of the wild, free and strong being, and one might argue that these characteristics are ascribed by association to whoever lives close to them. Though this is certainly true to some extent, in this case the importance of the horse to the human is more relational than representational.

In order to arrive at how our everyday practices form our understanding of the space we find ourselves in, Lorimer (2005) has introduced the term "more-than-representational". $\mathrm{He}$ argues that there is more to our interpretation of our surroundings than what they represent or what they might symbolise to us. The relation between horse and cowboy is very physical, and thus Carolan's (2008) understanding of our more-than-representational way of experiencing the rural is a useful tool to explore the displays of masculinity that are intertwined in this relationship: "In short, our understanding of space is more-than-representational. To ignore how the understandings of the countryside are embodied is to cut from our analysis a major (indeed the main) source of understanding." The concept of embodied experience of the world as a central aspect of human-animal relations is a useful tool to explore the cowboy-horse/cow relations in connection to masculine identities on the cowboy crew on the ranch. They cowboy-horse relation is created, mediated and maintained through physical communication and understanding. Keri Brandt (2004) writes of a non-verbal language of the interaction between horse and human, and concludes that the shared meaning is facilitated by the co-creation of a language system by way of the body. Further, the horse defines the cowboy as a horseman even when the horse is not physically close. The embodied and mutually constitutive relation of the rider and riding horse is conceptualised by Thompson as "centaurability" of the "rider-horse", which is taken to be an intercorporal being (Thompson 2011,223). Together, they embody the idea of the mythical creature centaur with the torso, head and arms of a human and the body of the horse. Interestingly, the author points out that Grave's (1968) account on centaurs suggests that the term refers to a Greek population 
Andrea Petitt: Cowboy masculinities in human-animal relations on a cattle ranch

working on horseback much like the American cowboys and that this mythical centaur was known to have an exaggerated masculinity. This further invokes the importance of the link between human-horse relations and masculine identities.

\section{THE HETERONORMATIVE, MACHO AND TRADITIONALLY MASCULINE COWBOY}

Accounts of rural masculinities, as Jacob Bull points out in his research on masculinities among fly fishermen in South West England $(2009,448)$, tend to focus on the moments when men are "most male", and emphasise strength, power, violence, mastery and the Heroic. These moments are plentiful in the everyday life of the cowboy. One story told to me on the ranch about a wild incident is particularly useful to illustrate the importance of the embodied relation between horse and man for the display of a traditional macho masculinity:

On his third day on the cowboy crew, Will's horse started bucking. As he tried to hang on, the other cowboys yelled at him to "kick him [the horse] in the guts". Caught up in the explosion of the horse's energy, Will didn't think and planted his heels in the horse's sides. Of course, the horse blew up even more, to the amusement of the other cowboys, and, bucking hard, ran towards the ravine ahead. Once they reached the edge of the ravine, the horse was still out of control and gave no sign of slowing down, so Will bailed off and threw himself to the ground. In the end, the horse did stop, and Will ended up with a concussion and painful head injuries. He was rushed to the hospital, a two-hour drive away, to get patched up, and was then sent home with a bandaged forehead and some painkillers. The next morning he had to "cowboy up" - quit complaining, get up, get going and get the job done. Since this was the kind of opportunity to show what you were made of, and since the pressure was always on, Will wouldn't call it a day until the job was done although he was still throwing up from the head injury a couple of days later. What is more, his experience was turned into a great song that helped pass the nightshift in the calving barn!

The stories of wild incidents on the ranch had the component of either the preparedness to endure pain and to put oneself in potentially dangerous situations, as in the example above, in which the cowboy failed to calm down the horse, or the ability to control and dominate the wild animal, in which case the story would usually end with the cowboy's mastery of the situation. Both cases include recognised themes within the traditional "macho" rural masculinity (Little and Leyshon 2003; Little 2007). This suggests that, in opposition to the dog owners discussed above, it is the interaction with the animal that is used to shape the gender identity of the cowboy, rather than the traits of the animal per se. It also puts a strong emphasis on the physical relation between human and animal and the embodied experience becomes a way to emphasise a macho masculinity.

In the above story, Will shows that he is willing to risk potential pain and discomfort by riding a horse that just came in from the mountains. From the very start, the interaction with the horse provides an opportunity to display traditional macho masculinity, 
or in Woodward's (1998) words from a study on military training as cited by Little and Panelli (2003), "pitting oneself against the elements". Riding the horse is a physical encounter for both the rider and the horse, and the communication is mostly tactile - a bodily experience. When the horse starts bucking, it would be understood by the rider through his body, and the situation does more than represent a "tough condition" - it is experienced as one. Had the story ended in success for the cowboy, had he taken control of the horse and showed his domination over it by staying in the saddle, it would have also been an excellent display of a macho masculinity. Even though it ended with the cowboy on the ground and the horse running free for a while, the story tells of the endurance of pain and the determination to do the job the next day. Thus a disastrous encounter with a horse may still serve as a display of a macho masculinity depending on how the rider deals with it afterwards. What is more, the colleagues' attempt to make a difficult situation even more difficult by giving bad advice (to press his heels into the horse's side) as well as their expectation that he would get on his horse the next day in spite of head injuries, shows the importance of displaying a tough masculinity, with the horse as both the setting and the instrument to do so.

\section{The MASCULINE POLITICS OF MOVEMENT}

Turning now to the cows, they also play a part in the macho masculinity of the cowboys. The relation between cow and cowboy is much different from that of the horse and the cowboy. Whereas the horse is a continuous companion and a working partner, the individual cow rarely has a personal relationship with the cowboy. The cow is seen as a part of a herd, often a troublesome creature and sometimes even stupid. One of the cowboy's main tasks is to move large herds of cows.

As Bull (2011) points out, movement is a crucial part of the human-animal relations of riding, herding, ranching, etc. In the daily interaction between cow and cowboy, movement is undoubtedly one of the most important focuses of attention. The proportional importance of aggressiveness and physical power in combination with the open display of these characteristics makes the movement of cows interesting for an analysis of the macho, traditionally masculine feature of the cowboy. Bull (ibid.) underlines the point that the choices animals (including humans) make, concerning whether to be still or to move, and in what way to move, may be viewed as political choices, and that these politics permit and restrain movement for different species and individuals according to their social, cultural and historical situation. These choices and restraints define the cow-cowboy relation to a large extent.

One of the main tasks of the cowboy is to make the cow walk in a certain way and with a certain speed. This is done with the help of the horse. By sitting on the horse and directing it to move in specific directions, the cow is expected to answer by moving in other specific directions. Now, when this does not run smoothly, i.e., if the cow walks in a different direction than that intended by the cowboy - be it because of miscommunication or because the cow prefers another idea rather than following the cowboy's 
suggestion - the politics of movement become apparent. Whether it was one cow that refused to go through a particular gate, or 400 cows that took a "wrong" turn, refused to go uphill, or spread out instead of walking in a group, the cowboys tended to respond by using more violent behaviour to get their way. This would consist in increasing the speed of the zigzagging behind the cows, and sometimes even riding the horse right into the body of the cow. There would also be screaming, hat-waving and kicking, if possible.

Often the horse would join in and display such aggressive behaviour as laying its ears backwards, jolting its head, and sometimes even biting a slow cow's behind. This suggests that the cowboy's violent behaviour is understood by the horse as directed towards the cow and not himself. Furthermore, it could suggest that the horse in that moment is somehow closer to the cowboy than to the cow and complements the instructions of its rider with actions meant to increase the wanted effect of those behaviours. In this way the cowboy, and to some extent also the horse, display domination and physical power over the cow, an image closely linked with that of the macho, traditionally masculine cowboy. These events are experienced through the bodily conception of what it means to make cows move, and it is the cowboy's body that is read by the horse, as is both the cowboy's and the horse's body by the cow. This wild, violent and aggressive situation, in which the man uses his determination, domination, physical strength and aggressive behaviour, is closely linked to the image of the cowboy, and to a macho masculinity. Further, the roping, branding and castration of calves also displays these macho dimensions of physical power and dominance and expresses the cowboys "right" to restrain the calf's movement and alter its body.

\section{Additional rural masculinities: The Calm, ReSponsible, LESS VIOLENT COWBOY}

In between the displays of hyper-masculine, macho, physical strength and domination accounted for above, there are, however, other moments that deserve attention. As Bull $(2009,455)$ argues, additional rural masculinities present within the same individual, create a "cadence of masculinity", which tends to get less attention and emphasis. Bull identifies some additional rural masculinities among his fly-fishing informants, which are not defined by violence, dominance or other hyper-masculine traits. Applying some of his categories, this section focuses on additional rural masculinities in the humananimal interaction on the ranch.

All of the cowboys took part in the branding and castrating of the calves in the summer, but the violent nature of these activities was not identified or spoken of as being exciting. In fact, branding the cattle was often spoken about in terms of inflicting a necessary pain that enabled the animals to roam free for the rest of their lives, and it was the ability to inflict as little pain as possible, to do the procedure as quickly as possible, and to keep the situation as calm as possible, that was identified as prestigious. The fact that they would keep the cows in the corral where the calves were being branded, could be an example of this, as it was meant to bring calmness and comfort to the calf prior to 
and after their painful experience. Only the best ropers, those who would not stress the animals with multiple tries to catch the calf, and thus chase them around, were allowed on the horses on the branding day, while the rest took up branding irons, vaccination shots or castrating knives. Without branding, the cowboys emphasised, the herds would have to be more controlled as they would be impossible to distinguish from the neighbours' cattle, should they accidently mix. It was thus the calmness and lack of violence towards the cattle that seemed to be appreciated cowboy qualities. It can of course be argued that the lack of violence also makes the day easier for the cowboy and possibly his conscience. Nevertheless, the respect that a calm handling earned often seemed to outrank the opportunity to display dominance and violence in wild situations.

Rather than using force and violence as a starting point, the cowboys often emphasised using "just enough" in order to control the cattle and horses. To do this required the ability to "read" the animals, and to know what they were about to do or to what they were reacting and why. The ability to be able to read cattle is also important; for example, in order to know which cow is about to give birth, and which cow needs help to deliver, are both crucial and recurring tasks during the calving season. While the view of the traditionally masculine male underlines the dichotomy of the man as the agent and his nature as passive, these instances draw our attention towards aspects of rural masculinity that "responds to nature, nurturing, shepherding and cultivating, rather than domineering and subjecting" (Bull 2009, 456).

The fishermen's appreciation of the outdoors and closeness to nature can also be found among the cowboys on the ranch. They would often express similar views when asked what they liked about their working life. One cowboy liked to "[...] just be outside all day. You get to watch the sunrise and sunset [...]," and another one thought that "early mornings are hard, but it's worth it, watching the sun come up is pretty peaceful". Yet another one assured me that "I always liked being outdoors; if I don't go back to the city I'm ok with that." The opportunity to be outdoors all day, experiencing nature from the back of a horse as well as being a long way from the business of the city, were recurrent themes in conversations about why they chose to be cowboys. The thought of having an "indoor job" seemed repugnant to most of the crew. Large parts of the year, the cowboys in the crew would camp out in tents or cabins in the mountains, following the cattle on their grazing route, and this was an element of work that was greatly appreciated. Everybody longed to "go to camp" and again emphasised the closeness to nature, the absence of people and the quiet solitude this entailed. Interestingly, these attractive attributes of the camping part of the year (May to December) were also seen as the reasons why there were no more girls (or any girls) working on the cowboy crew. The closeness to nature and the absence of humans and human facilities were seen as aspects of the working conditions attractive only to men, an important aspect of a rural masculinity, yet something that women would not like.

All the cowboys knew, of course, that the cows they were herding were on their way to become food, but it never came up in conversation. This ultimate power over and violence towards the animals that the cowboys facilitated - as do most stockmen in commercial farming - was not called upon in relation to their identity as cowboys or 
as men. Instead, the display of both professional skill and masculinity focused on the live animals.

In exploring people's relationship to livestock, Rhoda Wilkie (2005) underlines the paradoxes involved in caring for animals that are to be killed, and argues that the commodified status of livestock is flexible, depending on the changes in the human-animal relationship. Typically, she finds, as does Colter Ellis among his ranchers, that people who work with the rearing of animals as cowboys do, distance themselves both from the killing of the animal and from emotional attachment to it, showing a "concerned detachment" (ibid. 218; Ellis 2007). This entails, as I observed among my cowboy informants, perceiving the cattle as part of a herd rather than as individuals. However, human-cattle relations seemed to break down to a personal level in the calving barn, where each cow and calf would be carefully monitored and often helped to survive. Notably, I never witnessed any suggestion of violence or aggressiveness in the calving barn. Avoiding seeing the cattle as individual sentient subjects could be understood as facilitating the macho aggressiveness and violence towards the animals when being herded or branded, whereas the more individual and nurturing relationships in the calving barn would act as a barrier towards such violence, and instead allow for other expressions of masculinity, such as responsibility and calmness. In the calving barn, the cowboys took pride in assuming and fulfilling the responsibility of keeping cows and calves alive during night calving, when everybody else was sleeping. Ben pointed out that "you know, you're kinda' saving some lives, they wouldn't make it without ya' if you have to pull them."

Further, during my whole stay on the ranch, not a single cowboy was ever late for work and the horses were always fed and saddled before breakfast, showing a proud commitment to the lifestyle and a great sense of responsibility. No one would stop working until their task was completed, and only on one occasion did I hear someone ask for a sick day, although injuries and colds were common. It did not take long, however, before this person felt the pressure to quit. This "getting the job done", as Ben and Tony put it, was a frequent description of what it takes to be a cowboy, and the belief that women would need help to finish their tasks was an often used reason as to why there were no cowgirls on the crew, again suggesting a strong link between being a cowboy and being a "real man".

The caring part of the animal-cowboy relation in the calving barn, noted above, can also be found elsewhere and is interesting from a masculinity perspective. Although no cowboy would hesitate to be verbally or physically rough on the animals, should the situation crave it, there was an articulated code of care that frowned upon any additional violence towards the horses in their care. It seemed to be applicable to cows and dogs to a lesser extent, suggesting some sort of hierarchy among the different species. However, to ride your horse too hard, or to inflict pain on it without good reason was strongly frowned upon. On the other hand, there was no petting of the horses, and no extra brushing. The horse was not considered a pet, but rather a teammate, work companion or partner. The caring for the cows during spring included riding around, checking for sick calves, roping them and giving them injections, an activity that requires a skilled eye and hand. It also included bottle-feeding orphan calves and checking that the heifers did not have trouble calving. This part of the job was considered more feminine and 
suitable for women and was often given as an example of what women could do on a ranch. The work in the calving barn did not include a horse, in comparison to almost all other tasks involving cows.

As noted above, the human-horse relationship is often a complex matter, and so also when used to display multiple cowboy masculinities. The relationship to the horse was in the focus of many stories and conversations. Comparing experiences with bucking horses was popular, and a conversation about the remoteness of a certain camp quickly turned into story telling: "Dave got bucked off his horse up in camp, broke his back and had to crawl back to get to his truck and go for help [...]." Tips and ideas about how to get the horse to listen to the rider and trust him were also recurring subjects, and could include such advice as: "I stand close, like this, and let him [the horse] get used to the rope [...]. I've seen guys start over here, but [...]." The calmer and steadier the cowboy was, the more praise he acquired: "Barry is solid, shorter stirrups, hard fist; Jake, he is softer." Ben explained, nodding approvingly to Jake's softer approach: "He could move four hundred cows alone and you wouldn't even hear them bawling!", and continued: "Ken, he is really good in the calving barn, he can sit and watch a cow for an hour, I could never do that [...]." In all of these examples, the embodied experience rather than intellectual understanding of what is happening plays an important part, and this bodily understanding of being in the world helps to make sense out of the importance given to the human-animal interaction on the ranch.

\section{The SENSITIVE, ATTENTIVE COWBOY WITH FINESSE}

Bull (2009) also identifies the technical finesse used by the fishermen in his study, which requires calmness, delicacy and sensitivity, as another aspect of a rural masculinity. The human presence, he argues, is minimised and delicate rather than strong and muscular. In the case of the cowboy, this element can be found in a number of situations.

For instance, during the branding session, the branding, vaccination, castration and cutting of horns are all done simultaneously, to minimise stress for the animal. The calf and cow are kept together until the calf gets roped and tied on the ground. Within seconds, a team of people move in to perform their different tasks and within the minute the calf can go back to its mother. Even though no one would deny that this is a painful and stressful experience for the calf, the process is carefully thought through in order to minimise the extent of the bad experience. A technical finesse is also necessary in order to identify a sick calf, place the horse in position and aim and throw the rope accurately around the moving calf's head.

Returning to the cowboy-cow relationship and considering the politics of movement, the interaction can become rather violent, as we noted above, and it is this aspect of events that most often figures in stories and movies, and is probably what led to Malamud's, Birke's and Arluke's statements about the "cowboy way" of treating animals (Arluke 1992; Birke 2007). However, sensitivity and attentiveness also stand out as important and obvious qualities when observing activity over time and listening to the stories about 
talented cowboys. In violent situations, it was undoubtedly important for the cowboy to be able to be aggressive, but the ability to avoid such situations was an even more important source of pride. The ability to "read the cows" so well that it is possible from a distance to position yourself and your horse in a way that would make the cattle move in the desired direction takes a lot of attention and sensitivity towards the signalled intentions of an individual cow. Best of all, as pointed out by Ben in the quote above, was if you could move a large herd of cattle all by yourself, without spreading, speeding up, or even mooing them. To be able to keep "cow speed" on your horse appeared to be an important quality. It has to be said that there were different views among the crew on how quick you should be with applying a more aggressive method and when you should give the cows time. The choice of words to encourage the cows to speed up also varied, from what would be perceived by most English speakers as extremely rude and possibly vulgar, to tender encouraging utterances suggesting great compassion. The general opinion was to strive for situations that "required" less violence toward the cattle, although how different individuals defined the concept of "required" varied considerably.

The same kind of sensitivity to the cattle's movements occurred in the activity of "moving pairs", where a cow and a young calf were to be moved together to another pasture. First, it requires skill to identify which calf belongs to which cow, and second, it takes some skill to judge if they are ready to move together or not from the way in which they look at each other. Once this is done, the horse needs to be steered into the herd of cattle in a manner that will make only these two animals move without disturbing the rest, while keeping an appropriate distance from the pair so that they do not panic or separate. As described at the beginning of this paper, the "pair" movements are responded to step by step by the cowboy-horse equipage. In responding to the animal with the bare minimum of action, the human presence is minimised and delicate.

The same is true for the horse-cowboy relation. Though violent incidents make good stories, it is often, as we have seen, the violence against the cowboy that is important to the masculine identity, rather than his violence towards the horse. As we saw above, although a stern leadership is admired, exaggerated violence towards a horse is not associated with anything positive. This can be illustrated with the following example: the cowboy who got bucked off in the story above, kept having a hard time with his horse, and the horse kept trying to shake him off. He later exchanged horses with Dan, and instantly the horse stopped the acrobatics. Dan never showed a sign of having to use strength or aggressiveness to avoid violent situations. Although Will managed to stay on the horse, except for that one time, it was Dan that acquired respect from the cowboy crew. The calmness and the small signs he used to communicate with the horse seemed to be more impressive than "riding out" violent encounters with the same horse. John sat up on a horse that had never been ridden before and received the same treatment, and fell off too. However, he eventually managed to change their interaction pattern and direct the horse with small physical signals, for which he received much praise. A dual human-horse relation is also noted by Schuurman and Leinonen (2012) in their article on how humans experience the death of horses. Their informants perceived the horse both as a companion that wants the same kinds of things as humans do, and, on the other hand, as an animal distinctively different from themselves. For the cowboys 
I met, the duality seemed to boil down to the capacity to endure pain inflicted by the horse, while aiming at being a fine tuned intercorporal continuum - both embodied aspects of the relation. Apart from the simple controlling of the horse, the pattern common to the above anecdotes reveals a liking and appreciation of the delicate hand. Calvin expressed this when he told me that "every day I try to become a better cowboy [...], try to get the horse to become a bit lighter in the mouth" (i.e., to respond to a lighter touch of the cowboy's hand on the reins). Tony spoke along the same lines when he explained one important quality of a good cowboy:

The good guys [cowboys], the horse is kinda' part of them. If a cow wants to go out, the horse is in the gate and the cow is stopped, it just happens. Inexperienced guys have to think and react, think about it, and the cow is gone. You shouldn't have to think about the process, it should come natural.

What Tony is asking for is an impressive level of sensitivity between cowboy and horse, coupled with an attentiveness to each other that makes them merge into one bodily unit of experience. This, I suggest, is the cowboy version of embodying the centaur discussed above (Thompson 2011). Lynda Birke met similar explanations among participants in her study on human-horse relations in "natural horsemanship", where informants described themselves as becoming one with the horse. Birke views these statements as part of a discourse focusing on a human-horse relation of partnership, rather than that of predator and prey. The informants in her study used the partnership discourse when talking about a specific horse, but not when discussing horses in general. The cowboys, on the other hand, emphasised the horse and the rider as one even in general speech, and also in short-term working relations.

Ann Game also compares riding to the mythical creature of the centaur, half horse, half human, emphasising that "the rider is the riding", and thus exists at that point through the riding relationship to the horse. In the world of my cowboy informants, who often spent eight hours a day on a horse, this embodied relation with the horse defined them as cowboys, as well as the rest of their day and their other relations on the ranch. At the same time, as being tuned in to each other, both the rider and the horse need to be almost equally tuned in on the cow. Note that Tony above talks about if a cow wants to go out, rather than about a cow that is moving towards the gate. Many times the horse and rider would step sideways for a seemingly unnoticeable reason. However, it later became apparent that it was a certain look in a cow's eyes, a shifting of weight in the calf, or simply a stiff body that was the cause for the move. Without this attentive observation and the swift communication between rider and horse, which is performed with such finesse that the rider, according to Tony, does not even think about it, you are not one of the good cowboys. And to be a good cowboy was what every man on the crew strived for every single day. Tony's description of how the cowboy experiences his relationship with the horse mirrors Carolan's (2008) point above: “To ignore how the understandings of the countryside are embodied is to cut from our analysis a major (indeed the main) source of understanding." Relying on Tony's description, one could almost argue that the cowboy's understanding of the horse and the cow, in the moment 
of escape prevention, is only bodily. Implicitly, he also says that the horse should not have to think about what the cowboy means, or about the professional purpose of their relationship - the keeping of the cow.

Using Thompson's post-binary approach, this cowboy-horse continuum blurs the border between human and animal (Thompson 2011). Taking the non-binary analytical framework a step further, we need not stop at smudging the lines separating humans and horses, humans and cows, or humans and other species. Instead, we could extend our gaze to further explore how, for example, animals' relations to other species shift when they engage in relation with humans. As with the violent interaction used to move cattle described above, where the horse participated in the violence and bit the cow, the horse also takes on a similar complementary role when less aggression is required. When singling out a cow from the herd, the horse is, interestingly, sometimes more skilled than its rider, and after being showed the targeted individual, the horse can, without much help from the rider, separate the individual from the herd. This is also often the case when a calf needs to be roped. Once the horse understands what calf should be pursued, a skilled cow horse "locks on" and follows the calf in sometimes complicated patterns of movement, or through the herd, leaving the rider free to concentrate on his rope. In these two examples, we see how the horse teams up with the rider, affecting its relation to the cow, who seems to be of little interest to the horse whenever it is on its own. It also shows a strong connection between the rider and the horse, a teamwork that requires minimal visible communication and much sensitive, attentive finesse.

\section{Conchusions}

The traditional macho heteronormative masculinity is very present in the everyday interactions between cowboys, cows and horses. There are many moments on the ranch where aggressive, violent and dominant behaviour is displayed, and it is also clearly appreciated when the individual is able to handle situations that are judged to demand such behaviour. Both in the cowboy-horse relation and the cowboy-cow relation, an embodied masculinity is imperative for the cowboys in experiencing the physical aspects of what is traditionally known to be characteristics of a heterosexual, macho man. This aspect of masculinity underlines the ability to use aggressiveness and violence towards animals when needed. Moreover, an even stronger emphasis is attributed to the endurance of pain and physical hardship by the cowboy, which is inflicted on him as a result of his relationship with horses, cows and "nature". As such, it is the responsive act to an embodied relationship with animals and their surroundings from the cowboy that allows for a display of his macho masculinity, rather than his own aggressive or violent initiatives. Aggressive and violent behaviour was judged as positive among the crew only when it was considered necessary. Treating the cows, and especially the horses with more violence than the situation required, was severely frowned upon, suggesting limits to the macho masculine ideal.

This also suggests a differentiation in how the embodied relation with a horse and with a cow can be instrumental in the construction and display of different masculine 
ideals among the cowboys, crucial to the gendered power relations among the men. I thus suggest that it is of analytical interest to extend the non-binary approach to differentiate between species when diluting human-animal boundaries, as it means something in particular to the cowboy to gain this connection with a horse, but something completely different were it a cow. Whereas the cattle to a larger extent were targets of violent and aggressive initiatives through herding and branding, and thus allowed for a display of the traditional macho masculinity, the same treatment of horses did not wield the same assurance of masculinity, and could even result in excluding the person from being categorised as a "good cowboy" and thus a "real man". On the other hand, it has become clear that horses are an integral part of the cowboy identity, and that the embodied relationship with the horse encourages additional masculinities on the ranch, based on the notions of sensitivity and finesse. Calmness, attentiveness and responsibility are promoted in the cowboys through the relation with both horses and cattle. The mastery of the ideal communication through an almost exclusive bodily event, merging the horse and cowboy that experience together the movements of the cow, is a prime source of pride and praise among the cowboy crew.

This paper shows that by recognising these additional cowboy masculinities present in the relations between cowboy, horse and cow, it is possible to alter the exclusive status of the traditional macho, cowboy masculinity, and instead acknowledge a range of cowboy masculinities, all important for the human-animal relations on the ranch. Further, it has suggested an expansion of non-binary analytical frameworks by concluding that while the same species can offer a range of relations leading to the possibility of displaying different masculinities, different categories of animals are instrumental in different ways in the construction of different and additional masculinities among the cowboys. Lastly, the paper suggests expanding a non-binary approach by extending the analytical framework to exploring how animals' relations to other species shift when they engage in relation with humans. 
Andrea Petitt: Cowboy masculinities in human-animal relations on a cattle ranch

\section{REFERENCES}

ARLUKE, ARNOLD 1992: The ethical culture of primate labs. Paper given at Science and the Human-Animal Relationship meeting, Amsterdam.

BIRKE, LYNDA 2007: Into the Laboratory. - Kalof, Linda \& Fitzgerald, Amy (eds.), The Animals Reader. The Essential Classic and Contemporary Writings. Oxford, New York: Berg.

- 2008: Talking about Horses: Control and Freedom in the World of "Natural Horsemanship". - Society and Animals 16(2).

BRANDT, KERI 2004: A language of their own: An interactionist approach to humanhorse communication. - Society and Animals 12(4).

BULL, JACOB 2009: Watery masculinities: fly-fishing and the angling male in the South West of England. - Gender, Place and Culture 16(4).

- 2011: Introducing movement and animals. - Bull, Jacob (ed.), Animal MovementsMoving Animals: essays on direction, velocity and agency in humanimal encounters. Uppsala: Centre for Gender Research, Uppsala University.

CAROLAN, MICHAEL 2008: More-than-Representational Knowledge/s of the Countryside: How We Think as Bodies. - Sociologia Ruralis 48(4).

ELLIS, COLTER 2007: Negotiating contradiction: Human-nonhuman animal relationships in cattle ranching. Paper given at the Annual meeting of the American Sociological Association, New York.

EVANS, RHONDA \& KALICH, DEANN \& FORSYTH, CRAIG J. 2007: Dogfighting: Symbolic Expression and Validation of Masculinity. - Kalof, Linda \& Fitzgerald, Amy (eds.), The Animals Reader. The Essential Classic and Contemporary Writings. Oxford, New York: Berg.

GAME, ANN 2001: Riding: Embodying the centaur. - Body \& Society 7(4).

KALOF, LINDA \& FITZGERALD, AMY (eds.) 2007: The Animals Reader. The Essential Classic and Contemporary Writings. Oxford, New York: Berg.

LITTLE, JO 2007: Constructing nature in the performance of rural heterosexualities. - Environment and Planning D: Society and Space 25(5).

LITTLE, JO \& PANELLI, RUTH 2003: Gender Research in Rural Geography. Gender, Place and Culture 10(3).

LORIMER, HAYDEN 2005: Cultural geography: the busyness of being 'more-thanrepresentational'. - Progress in Human Geography 29(1).

MALAMUD, RANDY 2007: Zoo Spectatorship. - Kalof, Linda \& Fitzgerald, Amy (eds.), The Animals Reader. The Essential Classic and Contemporary Writings. Oxford, New York: Berg.

MALTERUD, KIRSI 1998: Kvalitativa metoder i medicinsk forskning. Lund: Studentlitteratur.

PEDERSEN, HELENA \& HOLMBERG, TORA 2010: Lecture given at PhD course in Human-Animal studies: Representations and Practices, Uppsala.

SCHUURMAN, NORA \& LEINONEN, RIITTA-MARJA 2012: The Death of the Horse: Transforming Conceptions and Practices in Finland. - Humanimalia 4(1). 
Andrea Petitt: Cowboy masculinities in human-animal relations on a cattle ranch

THOMPSON, KIRRILY 2010: Binaries, Boundaries and Bullfighting: Multiple and alternative human-animal relations in the Spanish mounted bullfight. - Anthrozoös 23(4).

-2011: Theorising Rider-Horse Relations: An ethnographic illustration of the centaur metaphor in the Spanish bullfight. - Taylor, Nick \& Signal, Tania (eds.), Theorising Animals. Leiden: Brill.

WILKIE, RHODA 2005: Sentient commodities and productive paradoxes: the ambiguous nature of human-livestock relations in Northeast Scotland. - Journal of Rural Studies 21(2).

WOODWARD, RACHEL 1998: 'It's a man's life!': soldiers, masculinity and the countryside. - Gender, Place and Culture 5(3).

Andrea Petitt is a PhD student at the Division of Rural Development at the Swedish University of Agricultural Sciences, and has a M.Sc. in Anthropology from the Université de Montréal. 